\begin{tabular}{|c|c|}
\hline 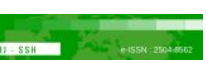 & Malaysian Journal of Social Sciences and Humanities (MJSSH) \\
\hline Malaysian Journal of & Volume 6, Issue 3, March 2021 \\
\hline (MJ-SSH) & e-ISSN : 2504-8562 \\
\hline & $\begin{array}{l}\text { Journal home page: } \\
\text { www.msocialsciences.com }\end{array}$ \\
\hline
\end{tabular}

\title{
Tahap Nilai Perniagaan Keusahawanan Cina dan Hubungannya terhadap Tingkah Laku Keusahawanan Masyarakat Cina di Malaysia
}

\author{
Tay Chu Chien ${ }^{1}$, Sheerad Sahid ${ }^{1}$, Norasmah Othman ${ }^{1}$ \\ ${ }^{1}$ Fakulti Pendidikan, Universiti Kebangsaan Malaysia (UKM) \\ Correspondence: Sheerad Sahid (sheerad@ukm.edu.my)
}

\begin{abstract}
Abstrak
Etika merupakan tatacara atau perbuatan dalam sesebuah masyarakat yang dapat memberi bimbingan kepada masyarakatnya mengenai perbuatan yang terpuji yang mesti diikuti dan dijadikan sebagai panduan. Dalam konteks etika dalam perniagaan, nilai sering dikaitkan dengan tingkah laku atau perbuatan manusia. Teori Tingkah Laku Terancang bermakna tingkah laku seseorang individu boleh dipengaruhi oleh tekad. Tingkah laku keusahawanan yang terlalu ghairah kepada tamak haloba dan berkiblatkan keuntungan diri sendiri dalam mengumpulkan harta kekayaan dan haloba perniagaan terus menjuruskepada isu tidak beretika. Kajian ini dijalankan bertujuan untuk menguji tahap nilai perniagaan dan hubungannya terhadap tingkah laku keusahawanan masyarakat Cina di Malaysia. Pengkaji menggunakan instrumen soal selidik dan data yang diperolehi daripada 350 responden dianalisis menggunakan statistik deskriptif dan inferensi. Hasil analisis menunjukkan bahawa tahap nilai perniagaan terdiri daripada empat domain iaitu guan xi, maruah, kejujuran dan amanah pada tahap tinggi. Manakala terdapat korelasi positif dan signifikan antara nilai perniagaan dengan tingkah laku keusahawanan masyarakat Cina. Ini bermakna masyarakat Cina mengamalkan nilai perniagaan semasa menjalankan perniagaan. Implikasi daripada kajian ini memberi kesedaran kepada masyarakat Cina, Melayu dan India di Malaysia tentang nilai perniagaan terhadap tingkah laku keusahawanan. Kajian ini juga dapat mengalakkan pihak agensi-agensi mengambil langkah untuk memupuk nilai tertentu supaya perniagaan dapat dijalankan dengan lebih lancar.
\end{abstract}

Kata kunci: nilai perniagaan, tingkah laku keusahawanan, masyarakat Cina

\section{Level of Chinese Entrepreneurship Business Value and Its Relationship to The Entrepreneurship Behavior of Chinese Community in Malaysia}

\begin{abstract}
Ethics is a system of moral principles where it provides guidance and affect the community to perform praiseworthy deeds. As for business ethics, values are often associated with human behavior or actions. Theory of Planned Behavior means that an individual's behavior can be influenced by passion. Entrepreneurial behavior that is about greed and self-interest in accumulating wealth will lead to unethical issues. This study was conducted to test the level of business value and its relationship to the entrepreneurial behavior of the Chinese community in Malaysia. Researcher used questionnaire instruments and data obtained from 350 respondents and analyzed using descriptive and inferential statistics. The results of the analysis show that the level of business value that is guan xi, dignity, honesty and trust at a high level. There is a positive and significant correlation between business values and
\end{abstract}


entrepreneurial behavior of the Chinese community. This means that the Chinese community practices business values while doing business. The implications of the study contribute to the Chinese, Malays and Indians in Malaysia about the business of entrepreneurial behavior. This study can also encourage agencies to take steps to cultivate certain values so that businesses can run more smoothly.

Keywords: business values, entrepreneurial hehavior, Chinese community

\section{Pengenalan}

Dalam abab ke-21 ini, walaupun matlamat perdana berniaga adalah berpaksikan keuntungan. Akan tetapi, etika perniagaan adalah sangat penting dalam diri seseorang usahawan kerana etika merupakan satu set nilai dan peraturan yang boleh diterima atau harus dipatuhi oleh komuniti peniaga dan dunia perniagaan (Mohd Zulfadli, 2010; Ferrel, 2010). Isu-isu yang tidak beretika seperti penipuan, rasuah dan sebagainya merupakan rintangan dalam perniagaan pada zaman globalisasi ini. Oleh itu, seorang usahawan harus berusaha mengembang, melaksana dan menilai tindakan keputusannya supaya selaras dengan nilai perniagaan (Mohd Mizan Aslam, 2012; Kirkley, 2016). Hal ini demikian kerana seseorang individu yang beretika dapat memartabatkan imej dan reputasi perniagaan sekali gus dapat meningkatkan keuntungan (Yusuf \& Bashir, 2008; Hartman, 2005). Sebaliknya tingkah laku peniaga yang tidak beretika boleh menjatuhkan reputasi perniagaan, kehilangan kepercayaan dan kehormatan daripada pelanggan sehingga menatijahkan kesan-kesan negatif dalam bidang perniagaan yang diceburinya (Giacalone, Robert \& Promislo, Mark \& Jurkiewicz, Carole, 2016).

Di Malaysia, penyertaan masyarakat dalam perniagaan sama ada perusahaan kecil seperti kedai runcit atau industri besar seperti pembinaan dikendalikan oleh masyarakat Cina. Menurut Geographical Association (2020), masyarakat Cina telah menguasai 70\% dalam bidang perniagaan. Penguasaan oleh masyarakat Cina dalam bidang perniagaan disebabkan perniagaan yang lazimnya diwarisi daripada nenek moyang (Wan Husin, 2013). Etika masyarakat Cina yang menekankan amanah, disiplin, hubungan, kegigihan dan ketekunan telah sebati dalam jiwa raga sejak dahulu kala membolehkan perniagaan terus berkembang sehingga kini (Wan Husin, 2013).

Walau bagaimanapun, dalam kajian Hulpke \& Lau (2008) ada menyatakan tidak mudah menjalankan perniagaan di negara China kerana terdapat banyak masalah etika perniagaan di negara Cina kerana terdapat kecacatan dalam etika perniagaan. Contohnya, ada kalangan mereka tidak berpegang pada prinsip perniagaan nenek moyang yang diwarisi sebaliknya mereka lebih bertunjangkan hubungan antara pihak yang berpengaruh supaya perniagaan dapat diluluskan serta dijalankan dengan lebih lancar. Ekoran itu, tercetuslah gejala rasuah dalam kalangan pengusaha di negara China (Harding, 2014). Hal ini demikian kerana budaya China mendorong usahawan membuat keputusan perniagaan berdasarkan hubungan. Walaupun hubungan penting dalam sesuatu perniagaan tetapi juga boleh menjadi faktor penyebab masalah etika perniagaan dan masalah pengurusan sumber manusia (Chow 2005). Sebagai contoh, pengusaha Cina akan mengisi jawatan kosong dalam syarikat perniagaan mereka dengan pengambilan saudara-mara atau seseorang yang mempunyai hubungan yang rapat dengannya. Ini kerana menganggap bahawa saudara-mara atau kenalan adalah orang-orang yang boleh dipercayai. Sebaliknya bagi orang yang tidak dikenali, lazimnya mereka bersikap syak wasangka dan menguatiri golongan ini boleh mengancam perkembangan perniagaan mereka (Hulpke \& Lau 2008).

Kebanyakan kajian nilai perniagaan yang dilakukan di Malaysia tertumpu kepada perniagaan Islam sahaja. Manakala kajian mengenai nilai perniagaan dalam masyarakat Cina di Malaysia adalah sangat terhad. Oleh itu, tujuan kajian ini adalah untuk mengkaji tahap nilai perniagaan keusahawanan Cina dan hubungannya terhadap tingkah laku keusahawanan masyarakat Cina di Malaysia supaya dapat memperkasakan kesedaran kepada semua masyarakat tentang nilai perniagaan terhadap tingkah laku keusahawanan masyarakat Cina. 


\section{Sorotan Literatur}

\section{Nilai Perniagaan}

Penerapan nilai perniagaan yang syumul seperti amanah, kejujuran, hubungan yang intim, maruah yang menjadi pegangan Falsafah Konfusianisme memberikan peluang kepada seseorang peniaga untuk membezakan tindakan atau keputusan yang dibuat itu mendatangkan impak positif atau impak negatif dalam dunia perniagaan (Norita et al, 2010).

Antaranya ialah "Guan Xi” merupakan konsep universal dalam masyarakat Cina (Hulpke \& Lau, 2008). Hal ini melibatkan komitmen penjual dan pembeli dalam bentuk kewajipan bersama dan jaminan (Liao, 2016). Hubungan jaringan yang kuat antara perniagaan Cina merupakan keupayaan peniaga Cina untuk mempertahankan perniagaan dan memudahkan perniagaan dari segi peluang dan kos menjalankan perniagaan kerana ia berdasarkan kepercayaan dan bukannya kontrak (Wan Husin, 2013). Bagi peniaga Cina, usaha mewujudkan hubungan adalah untuk mencapai keharmonian dalam perniagaan. Biasanya, peniaga Cina mengadakan jamuan dan minuman yang formal untuk menjalinkan hubungan yang lebih mesra dan intim agar mewujudkan tahap kepercayaan tertentu sebelum menandatangani kontrak antara penjual dan pembeli (Li dan Chen, 2008). Selain itu, tingkah laku seperti potongan harga produk untuk mencapai kedudukan yang baik atau syarikat menawarkan hadiah untuk menerima perkhidmatan kembali biasa dilakukan kerana peniaga Cina mempercayai tingkah laku ini dapat mewujudkan hubungan yang baik untuk memperoleh kerjasama yang kukuh (Ruvolo, 2018).

Selain itu, "Mian Zi" didefinisikan sebagai maruah atau harga diri dalam sesuatu kelompok semasa berinteraksi dengan orang lain (Gallo, 2016). Dalam masyarakat Cina, konsep menjaga maruah penting dalam interpersonal interaksi, penilaian nilai dan pemeliharaan reputasi dalam tingkah laku organisasi dan keputusan pemasaran yang akan dibuat (Wong, Leung dan Ngai 2007). Selain itu, menjaga maruah merangkumi sikap atau tindakan tertentu yang membolehkan peniaga Cina untuk mencipta reputasi yang lebih baik di mata orang lain (Guo \& Lin, 2015). Konsep kehilangan maruah atau malu bermaksud tidak senang terhadap beberapa tindakan buruk yang boleh menjejaskan reputasi sosial dan hubungan yang telah dibina oleh peniaga Cina dalam dunia perniagaan selama-lamanya (Liao, 2016). Peniaga Cina sentiasa menghindari kesalahan yang mungkin boleh menyebabkan kehilangan maruah seseorang pelanggan (Gallo, 2016). Dengan demikian, peniaga mampu melestarikan keharmonian dengan pelanggan sekali gus menjalinkan aktiviti perniagaan dengan selama-lamanya.

Di samping itu, "Xin" iaitu kejujuran turut dijadikan pegangan sejak turun-temurun bagi golongan peniaga (Lee, 2015). Dengan adanya nilai kejujuran, peniaga tidak akan memperdaya atau mengelirukan orang lain kerana kejujuran adalah berasaskan sesuatu perkara, kata-kata atau perbuatan yang benar tanpa sebarang penipuan. Sifat jujur ini senantiasa dijadikan sifat yang wajib dimiliki oleh seseorang individu kerana sifat ini akan menjadi sumber daripada sikap amanah atau dapat dipercayai (Ruvolo, 2018). Hal ini demikian kerana orang yang jujur mudah dipercayai orang lain. Justeru, nilai ini disebatikan dalam generasi muda sejak kecil lagi. Jika ditinjau daripada perspektif yang lain pula, kesungguhan untuk berlaku kejujuran tidak seharusnya dibuat hanya untuk mematuhi undang-undang. Akan tetapi, nilai ini hendaklah disemarakkan sebagai suatu prinsip untuk memperkasakan perlindungan pengguna agar sebarang urus niaga itu tepat, jitu tanpa penipuan. Maklumat yang tertera dalam sesuatu produk itu mestilah lengkap dan tepat agar pelanggan boleh membuat keputusan yang bijak lanfas tidak akan tertimbullah kekeliruan dan salah tanggapan (Park \& Luo, 2001).

Akhir sekali, "Cheng" amanah merupakan sikap bertanggungjawab turut ditekankan dan menjadi salah satu etika keusahawanan masyarakat Cina di Malaysia (Lee, 2015). Berbekalan nilai ini, maka akan terserlahnya sifat kepercayaan dan keyakinan orang lain kepada peniaga. Nilai ini dapat menjaga prestij atau reputasi keusahawanan supaya peniaga akan komited untuk menyediakan dan membekalkan sesuatu produk atau perkhidmatan sekali gus membereskan segala urus niaga dengan penuh tanggungjawab, cekap, inovatif, konsisten dan ampuh dengan keperluan peniaga (Ruvolo, 2018). Nilai amanah ini mampu membantu membangunkan keberkesanan dalam memenuhi tuntutan bidang keusahawanan disamping mewujudkan perhubungan yang intim kedua-dua pihak yang terlibat. Seyogianya nilai 
amanah mampu menyediakan suasana keusahawanan yang kondusif serta lancar, boleh diyakini, mudah dan menguntungkan dari segi harga dan kualiti. Seperkara lagi, nilai ini turut memberikan jaminan kepada pelanggan bahawa pelanggan boleh bergantung sepenuhnya kepada peniaga. Nilai ini turut menjamin keadilan dan ketelusan dalam melatih diri untuk menjadi seseorang yang bertangjungjawab, jujur dan ikhlas kepada diri sendiri, masyarakat dan negara Wang, Zhou dan Huang (2012). Dengan demikian, pelanggan tidak akan menjauhkan diri daripada peniaga dan masyarakat tidak akan memandang serong kepada peniaga.

\section{Tingkah Laku Keusahawanan}

Menurut Miltenberger (2001), tingkah laku dapat ditafsirkan sebagai perbuatan yang dilakukan oleh seseorang individu. Tambah beliau lagi, tingkah laku tersebut dapat diteliti lebih daripada satu dimensi dengan memerhatikannya, menggambarkan, mengukur dan mencatatkannya mengikut suatu jangka masa serta meneliti kekuatan bentuk tingkah laku yang terserlah. Manakala, peristiwa yang berlaku di sekitar alam boleh membawa impak secara sistematik kepada tingkah laku seseorang individu. Sementara lagi, tingkah laku tersebut boleh tertonjol sama ada secara terbuka atau secara terpendah. Walau bagaimanpun, beliau berpendapat bahawa pengukuran perubahan tingkah laku hanya merangkumi jenis yang ditunjukkan secara jelas atau terbuka.

Luthjem dan Franke (2002) menjelaskan bahawa salah satu tingkah laku yang merupakan sebahagian tindakan keusahawanan ialah pemikiran kerjaya keusahawanan. Menurutnya, tingkah laku pemilihan kerjaya keusahawanan dikenal pasti sebagai satu set tingkah laku yang berkait rapat dengan pembentukan organisasi. Justeru, beliau mengesyorkan supaya kaedah tingkah laku yang lebih ampuh dipraktikkan dalam kajian keusahawanan seperti proses pemilihan kerjaya akibat kelemahan dalam pendekatan trait. Kajian Peterman dan Kennedy (2003), membuktikan pendedahan awal dalam bidang keusahawanan akan memberi dorongan kepada sikap, personaliti dan tahap keinginan mereka dalam pembentukan tingkah laku semasa memilih kerjaya bekerja sendiri.

Mair (2002) menyatakan bahawa kepentingan aspek pengurusan dalam membentuk tingkah laku keusahawanan telah dikenal pasti sebagai satu aspek yang penting. Kajian ini telah menunjukkan bahawa sokongan sosio-politik dan kemudahan laluan kepada sumber boleh mendorong tingkah laku keusahawanan. Kajian Hisrich et al. (2008) dan Nor Hazwani dan Sheerad (2020) pula membuktikan bahawa faktor yang menentukan seseorang dalam pemilihan bidang keusahawanan ialah tingkah laku pemilihan kerjaya keusahawanan serta prosesnya. Proses keusahawanan akan bermula dengan kehendak disusuli proses pengenalpastian dan penilaian peluang sehingga keputusan dibuat untuk membina usaha inovasi bagi menceburi kerjaya keusahawanan.

Menurut Brown \& Hanlon (2004) keberkesanan tangjungjawab seseorang usahawan terhasil daripada tingkah laku mereka sendiri yang menentukan kejayaan usaha teroka. Tambahan lagi, proses pemilihan kerjaya dan asas untuk peningkatan akan membawa kepada usaha yang seterusnya. Bagi Diochon et al. (2002) pula, tindakan tingkah laku keusahawanan akan memungkinkan individu untuk berubah dan dapat diukur melalui factor-faktor yang menjurus kepada kemungkinan untuk berubah.

\section{Teori Tingkah Laku Terancang}

Teori tingkah laku terancang merupakan suatu teori yang dipelapori oleh Ajzen (1991). Teori ini merupakan lanjutan daripada teori alasan tindakan (Ajzen \& Fishbein, 1980) Teori tingkah laku terancang dan bersistematik merupakan satu model teoritikal yang seringkali berkait rapat dengan psikologi sosial yang menjelaskan keadaan seseorang individu yang tidak mampu untuk mengekang kawalan sepenuhnya kepada sahsiah seseorang individu.

Dalam teori tingkah laku terancang, niat akan mendorong seseorang individu dalam melakukan sesuatu tingkah laku. Niat merupakan wakil bagi kognitif kesediaan seseorang untuk melakukan tingkah laku tertentu, dan ia dianggap sebagai premis terhadap tingkah laku (Ajzen \& Fishbein, 1980; Ajzen 2002; 2011). Niat juga diandaikan sebagai satu faktor motivasi yang mempengaruhi tingkah laku manusia dan ia merupakan tanda-tanda bagaimana individu sanggup mencuba, berapa banyak usaha yang sanggup 
diberi oleh individu untuk melakukan sesuatu tingkah laku. Semakin tinggi niat bagi seseorang individu terhadap sesuatu tingkah laku, semakin tinggi individu tersebut untuk melakukan tingkah laku. Dengan itu, niat dengan tingkah laku mempunyai hubungkait antara satu sama lain. Misalnya, seseorang individu boleh membuat keputusan sama ada melaksanakan atau tidak melaksanakan tingkah laku tersebut.

Walaupun sesetengah tingkah laku mungkin sebenarnya memenuhi keperluan dengan baik, tetapi prestasinya juga bergantung kepada faktor-faktor bukan motivasi yang dikenali sebagai peluang dan sumber untuk melakukan tingkah laku. Misalnya, masa, wang, kemahiran dan kerjasama dengan orang lain (Ajzen, 1985). Sebenarnya, faktor-faktor ini merupakan kawalan yang mempengaruhi tingkah laku individu. Sekiranya seseorang individu mempunyai peluang dan sumber yang diperlukan, dan berhasrat untuk melaksanakan tingkah laku, dia akan berjaya untuk membuat demikian.

Dalam teori tingkah laku terancang, tingkah laku seseorang individu adalah bergantung pada motivasi (niat) dan keupayaan (kawalan tingkah laku). Ia merupakan asas untuk membina teori yang berkaitan dengan tahap aspirasi (Lewin, Dembo, Festinger, \& Sears, 1944), prestasi psikomotor dan tugasan kognitif (Fleishman, 1958; Locke, 1965; Vroom, 1964), dan persepsi orang lain dan atribusi (Heider, 1944; Anderson, 1974). Terdapat andaian yang menyatakan bahawa motivasi dan keupayaan akan mempengaruhi prestasi tingkah laku individu. Oleh itu, niat dijangka akan mempengaruhi prestasi kepada sesuatu tahap dimana individu yang mempunyai kawalan tingkah laku, dan prestasi perlu meningkatkan kawalan tingkah laku individu kepada sesuatu tahap dimana individu tersebut bermotivasi untuk mencuba. Walaupun munasabah intuitif, hipotesis interaksi ini telah menerima sokongan empirikal terhad (Locke, Mento \& Katcher, 1978).

Sementara itu, dalam teori tingkah laku terancang, tingkah laku manusia adalah berpandukan kepada tiga pemboleh ubah, iaitu kepercayaan tentang akibat yang mungkin berlaku terhadap tingkah laku (kepercayaan tingkah laku), kepercayaan tentang jangkaan normatif orang lain (kepercayaan normatif), dan kepercayaan tentang faktor-faktor yang boleh memudahkan atau menghalang prestasi tingkah laku (kepercayaan kawalan). Dalam ketiga-tiga pemboleh ubah ini, kepercayaan tingkah laku akan mempengaruhi sikap yang suka atau tidak suka terhadap tingkah laku tertentu, kepercayaan normatf akan dipengaruhi oleh tekanan sosial atau norma subjektif dan kawalan tingkah laku akan mempengaruhi sama ada individu tersebut melakukan atau tidak melakukan tingkah laku tertentu. Apabila sikap terhadap tingkah laku, norma subjektif dan kawalan tingkah laku digabungkan, maka ia akan membentuk kepada kawalan niat (Azjen, 1991).

Menurut Ajzen (1991) dalam teori tingkah laku terancang, sikap terhadap tingkah laku merujuk kepada darjah pernilaian individu terhadap tingkah laku yang berkenaan. Peningkatan tingkah laku kepatuhan adalah berdasarkan usaha dan penilaian baik atau tidak baik seseorang ke atas sesuatu gelagat, justeru teori tingkah laku terancang ini dapat menguji penerapan etika perniagaan terhadap tingkah laku keusahawanan masyarakat Cina. Seterusnya, pemboleh ubah kedua norma subjektif juga diistilah sebagai faktor sosial. Norma subjektif ialah tekanan sosial untuk melaksana atau tidak melaksanakan tingkah laku berkenaan. Kawalan tingkah laku merupakan pemboleh ubah ketiga dalam teori tingkah laku terancang. Kawalan tingkah laku dianggap adalah darjah kawalan individu terhadap sesuatu tingkah laku yang akan dilakukan. Secara umum, semakin baik sikap dan norma subjektif terhadap tingkah laku berkenaan, dan semakin tinggi kawalan tingkah laku, semakin tinggi niat seseorang individu melakukan tingkah laku tertentu. Oleh hal yang demikian, didapati bahawa terdapat kepentingan relatif antara sikap, norma subjektif, dan kawalan tingkah laku dalam ramalan niat dijangka akan berubah mengikut tingkah laku dan situasi.

Model konseptual kajian ini adalah dirangka berdasarkan Teori Tingkah Laku Terancang yang dibina oleh Azjen (1991). Teori berikut ada menyatakan nilai perniagaan mempunyai kaitan dengan tingkah laku keusahawanan. Dalam kajian ini, pemboleh ubah bebas adalah nilai perniagaan. Sehubungan dengan itu, pemboleh ubah bersandar adalah tingkah laku keusahawanan seperti yang ditunjukkan dalam rajah 1 . 
DOI: https://doi.org/10.47405/mjssh.v6i3.696

Rajah 1: Kerangka Konseptual Kajian

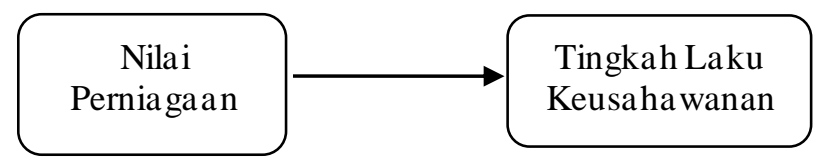

\section{Metod Kajian}

Kajian ini bertujuan untuk menguji tahap nilai perniagaan keusahawanan Cina dan hubungannya terhadap tingkah laku keusahawanan Cina. Oleh itu, kajian kuantitatif dijalankan dengan menggunakan instrumen soal selidik. Populasi konteks kajian ini adalah 2.6juta (He, 2012; Chin, 2013) terdiri daripada usahawan Cina di Malaysia. Berdasarkan jadual saiz sampel Krejcie \& Morgan (1970), jumlah sampel adalah sebanyak 400 orang usahawan Cina untuk menjalankan kajian tersebut. Pemilihan sampel dibuat secara rawak mudah. Sebanyak 400 borang soal selidik telah diedarkan, 350 borang soal selidik dijawab manakala 50 borang soal selidik tidak dapat digutip balik.

Kajian ini mengkategorikan soal selidik kepada tiga bahagian iaitu bahagian A melibatkan item nilai perniagaan manakala bahagian B ialah item tingkah laku keusahawanan dan bahagian $\mathrm{C}$ ialah item demografi responden. Bahagian A dan Bahagian B menggunakan Skala Likert lima dengan 1= sangat tidak setuju, $2=$ tidak setuju, $3=$ kurang setuju, $4=$ setuju dan $5=$ sangat setuju. Skala Likert digunakan kerana pengkaji boleh memperoleh respons daripada responden yang menyatakan darjah persetujuan mereka mengenai penyataan-penyataan dalam soal selidik. Terdapat 20 item yang terdiri daripada kombinasi empat domain seperti Guan Xi, maruah, kejujuran dan amanah di bahagian A dan 10 item di bahagian B. Jumlah keseluruhan soal selidik kajian adalah sebanyak 35 soalan.

Pengkaji telah menggunakan kesahan konstruk dalam kajian ini. Menurut Julie (2010), kesahan konstruk merupakan hipotesis secara teori yang diperolehi mengenai sifat berubah-ubah yang mendasari atau membina terhadap kriteria tunggal di mana melibatkan ujian skala. Jadual 1 menunjukkan hasil analisis kajian rintis bagi setiap item nilai perniagaan dan Jadual 2 menunjukkan hasil analisis kajian rintis bagi setiap item tingkah laku keusahawanan. Hasil analisis kajian rintis yang ditunjukkan dalam Jadual 1 dan Jadual 2 mendapati korelasi item dengan jumlah skor bagi setiap item melebihi 0.5. Menurut de Vaus (2004), nilai korelasi item dengan jumlah skor antara 0.5 hingga 0.7 dianggap boleh diterima. Maka, item soal selidik dalam kajian rintis telah dicapai.

Jadual 1: Analisis Kesahan Konstruk bagi setiap item Nilai Perniagaan

\begin{tabular}{llc}
\hline No Item & Korelasi Item dengan Jumlah Skor & Nilai Alpha Jika Item Digugurkan \\
\hline A1 & 0.509 & 0.897 \\
A2 & 0.573 & 0.920 \\
A3 & 0.547 & 0.896 \\
A4 & 0.662 & 0.893 \\
A5 & 0.491 & 0.898 \\
A6 & 0.548 & 0.896 \\
A7 & 0.560 & 0.896 \\
A8 & 0.616 & 0.894 \\
A9 & 0.599 & 0.895 \\
A10 & 0.520 & 0.897 \\
A11 & 0.534 & 0.897 \\
A12 & 0.551 & 0.897 \\
A13 & 0.583 & 0.896 \\
A14 & 0.713 & 0.893 \\
A15 & 0.424 & 0.899 \\
A16 & 0.608 & 0.895 \\
A17 & 0.636 & 0.895
\end{tabular}


DOI: https://doi.org/10.47405/mjssh.v6i3.696
A18
0.714
0.892
A19
0.741
0.892
A20
0.663
0.893

Jadual 2: Analisis Kesahan Konstruk bagi setiap item Tingkah Laku Keusahawanan

\begin{tabular}{lll}
\hline No Item & Korelasi Item dengan Jumlah Skor & Nilai Alpha Jika Item Digugurkan \\
\hline B1 & 0.579 & 0.947 \\
B2 & 0.730 & 0.942 \\
B3 & 0.807 & 0.937 \\
B4 & 0.722 & 0.941 \\
B5 & 0.826 & 0.936 \\
B6 & 0.863 & 0.934 \\
B7 & 0.827 & 0.936 \\
B8 & 0.843 & 0.935 \\
B9 & 0.770 & 0.938 \\
B10 & 0.777 & 0.938 \\
\hline
\end{tabular}

Dalam kajian ini, kebolehpercayaan instrumen diukur dengan menggunakan Cronbach's Alpha. Menurut Hair et al., (2010), Cronbach's Alpha merupakan sebuah ukuran kebolehpercayaan yang mempunyai nilai berkisar dari sifar hingga satu. Sementara itu, Hair et al., (2010) juga menyatakan bahawa nilai Cronbach's Alpha iaitu nilai kebolehpercayaan mesti lebih daripada 0.6. Berdasarkan kepada Jadual 3, nilai pekali kebolehpercayaan Conbrach's Alpha bagi pemboleh ubah bebas daripada analisis tersebut adalah 0.901 (nilai perniagaan) manakala pemboleh ubah bersandar daripada analisis tersebut 0.944 (tingkah laku keusahawanan). Oleh yang demikian, soal selidik yang digunakan dalam kajian ini adalah boleh diterima dan sesuai untuk menjalankan kajian sebenar kerana semua nilai pekali Conbrach's Alpha bagi pemboleh ubah bebas adalah melebihi 0.6.

Jadual 3: Analisis Kebolehpercayaan Cronbach Alpha Kajian Rintis

\begin{tabular}{llll}
\hline Pemboleh Ubah & No. Item & Bilangan Item & Nilai Alpha \\
\hline Nilai Perniagaan & A1-A20 & 20 & 0.901 \\
Tingkah Laku Keusahawanan & B1-B10 & 10 & 0.944 \\
\hline
\end{tabular}

Statistik deskriptif ini digunakan adalah untuk mendapatkan bilangan serta peratusan yang menerangkan nilai perniagaan. Skor min dan sisihan piawai digunakan untuk mengenal pasti tahap nilai perniagaan keusahawanan Cina di Malaysia. Jadual 4 menunjukkan Interpretasi skor min yang dikemukakan oleh Sirkin (2005) telah digunakan. Dalam kajian ini, ujian kolerasi dijalankan untuk melihat hubungan antara nilai perniagaan terhadap tingkah laku keusahawanan Cina.

Jadual 4: Interpretasi Skor Min

\begin{tabular}{ll}
\hline Skor Min & Interpretasi Skor Min \\
\hline $1.00-2.00$ & Rendah \\
$2.01-3.00$ & Sederhana Rendah \\
$3.01-4.00$ & Sederhana Tinggi \\
$4.01-5.00$ & Tinggi \\
\hline
\end{tabular}

Sumber: Sirkin (2005)

Kolerasi Pearson digunakan untuk tujuan mengukur kekuatan dan arah hubungan linear dari dua pemboleh ubah. Dalam kajian ini, ujian kolerasi dijalankan untuk melihat hubungan antara tahap nilai perniagaan terhadap tingkah laku keusahawanan masyarakat Cina di Malaysia. Jadual 5 menunjukkan aras aras kekuatan nilai pekali korelasi yang digunakan untuk kajian tersebut. 
Jadual 5: Kekuatan Nilai Pekali Kolerasi

\begin{tabular}{cc}
\hline Saiz Pekali Kolerasi & Kekuatan Kolerasi \\
\hline 0.91 hingga 1.00 atau -0.91 hingga -1.00 & Sangat kuat \\
0.71 hingga 0.90 atau -0.71 hingga -.090 & Kuat \\
0.51 hingga 0.70 atau -0.51 hingga -0.70 & Sederhana \\
0.31 hingga 0.50 atau -0.31 hingga -0.50 & Lemah \\
0.01 hingga 0.30 atau -0.01 hingga -0.30 & Sangat lemah \\
0.00 & Tiada kolerasi \\
\hline
\end{tabular}

Sumber: Chua (2012)

\section{Dapatan Kajian}

\section{Tahap Nilai Perniagaan Keusahawanan MasyarakatCina di Malaysia}

Jadual 1 menunjukkan dapatan yang terperinci bagi tahap nilai perniagaan keusahawanan masyarakat Cina di Malaysia. Sebanyak dua puluh pernyataan telah dianalisis untuk menjawab objektif kajian pertama. Secara amnya, min keseluruhan ialah 4.54 dengan sisihan piawai 0.39 bagi nilai perniagaan keusahawanan masyarakat Cina. Dapatan ini menunjukkan bahawa secara kesuluruhan keusahawanan masyarakat Cina mempunyai tahap nilai perniagaan yang tinggi dengan buktinya peratus persetujuan bagi 17 item melebihi 90.0 peratus. Frekuensi tertinggi ialah item 12 iaitu 99.7 peratus ( $S=29.7$ peratus dan $\mathrm{SS}=70.0$ peratus) responden bersetuju dengan kenyataan ini "Saya sentiasa jujur semasa berniaga". Ini diikuti oleh item 17 iaitu 99.1 peratus ( $S=27.7$ peratus dan $S S=71.4$ peratus) responden bersetuju dengan kenyataan ini "Saya sentiasa amanah semasa berniaga". "Saya menggunakan bahasa yang sopan ketika berurus niaga" (item 10) merupakan frekuensi ketiga tertinggi iaitu 96.9 peratus ( $\mathrm{S}=26.9$ dan $\mathrm{SS}=70.0$ ). Peniaga Cina sentiasa menghindari kesalahan yang mungkin boleh menyebabkan kehilangan maruah seseorang pelanggan (Gallo, 2016). Manakala frekuensi paling rendah ialah item 2 iaitu 73.5 peratus ( $\mathrm{S}=26.9$ dan $\mathrm{SS}=46.6)$ dengan kenyataan ini "Saya membentuk hubungan pelanggan yang luas sebelum mengadakan sebarang promosi". Selain itu, item 5 iaitu 87.5 peratus ( $\mathrm{S}=36.9$ dan $\mathrm{SS}=87.5$ ) dengan kenyataan ini "Layanan yang saya berikan berjaya menarik lebih ramai pelanggan" dan item 20 iaitu 89.7 peratus ( $\mathrm{S}=36.3$ dan $\mathrm{SS}=53.4$ ) dengan kenyataan ini "Saya mempercayai bahawa pelanggan saya akan memberi komen yang benar terhadap barangan atau perkhidmatan yang saya berikan". Peratus persetujuan bagi kesemua tiga item ini kurang daripada 90.0 peratus. Secara keseluruhan, tahap nilai perniagaan keusahawanan masyarakat Cina berada pada tahap tinggi. Fenomena ini bermakna usahawan masyarakat Cina mengamalkan nilai perniagaan yang diwarisan daripada Falsafah Konfusian semasa menjalankan perniagaan.

Jadual 1: Tahap Nilai Perniagaan Keusahawanan Masyarakat Cina di Malaysia

\begin{tabular}{|c|c|c|c|c|c|c|c|c|c|c|c|}
\hline \multirow[t]{2}{*}{ Bil } & \multirow[t]{2}{*}{ Item } & \multicolumn{2}{|c|}{ STS } & \multicolumn{2}{|c|}{ TS } & \multicolumn{2}{|c|}{ KS } & \multicolumn{2}{|c|}{$\mathbf{S}$} & \multicolumn{2}{|c|}{ SS } \\
\hline & & Bil & $\%$ & Bil & $\%$ & Bil & $\%$ & Bil & $\%$ & Bil & $\%$ \\
\hline 1 & $\begin{array}{l}\text { Saya menjalin } \\
\text { hubungan yang baik } \\
\text { dengan pelanggan. }\end{array}$ & - & - & - & - & 26 & 7.4 & 99 & 28.3 & 225 & 64.3 \\
\hline 2 & $\begin{array}{l}\text { Saya membentuk } \\
\text { hubungan pelanggan } \\
\text { yang luas sebelum } \\
\text { mengadakan sebarang } \\
\text { promosi. }\end{array}$ & 7 & 2.0 & 10 & 2.9 & 76 & 21.7 & 94 & 26.9 & 163 & 46.6 \\
\hline 3 & $\begin{array}{l}\text { Saya membekalkan } \\
\text { barangan atau } \\
\text { perkhidmatan kepada } \\
\text { pelanggan saya dengan }\end{array}$ & - & - & - & - & 13 & 3.7 & 87 & 24.9 & 250 & 71.4 \\
\hline
\end{tabular}


jujur, adil dan berintegriti.

4 Saya sentiasa melayan pelanggan dengan $\begin{array}{llllll}29 & 8.3 & 95 & 27.1 & 226 & 64.6\end{array}$ mesra dan sabar.

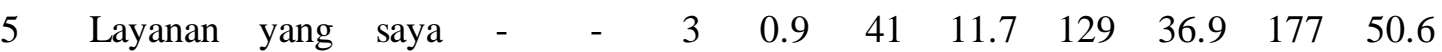
berikan berjaya menarik lebih ramai pelanggan.

6 Saya sentiasa memelihara

kehormatan diri dan menjaga maruah pelanggan.

7 Saya sentiasa mengelakkan daripada melakukan kesalahan yang mungkin boleh menyebabkan

kejatuhan maruah pelanggan.

8 Saya dapat mencipta reputasi perniagaan yang baik melalui pemeliharaan

kehormatan diri dan penjagaan maruah pelanggan.

9 Say dapat melestarikan

keharmonian dengan pelanggan melalui pemeliharaan kehormatan diri dan penjagaan maruah pelanggan.

10 Saya menggunakan bahasa yang sopan ketika berurus niaga.

11 Saya seorang yang jujur.

12 Saya sentiasa jujur semasa berniaga.

13 Saya membekalkan barangan atau perkhidmatan yang berkualiti sahaja kepada pelanggan.

14 Saya menawarkan barangan atau perkhidmatan pada harga yang berpatutan.

15 Saya tidak merahsiakan sebarang fakta tentang kelemahan atau 
implikasi yang

mungkin timbul dalam

perkhidmatan yang

diberikan.

16 Saya seorang yang

boleh dipercayai.

17 Saya sentiasa amana semasa berniaga.

18 Saya memperole kepercayaan dan

keyakinan yang kukuh daripada pelanggan.

19 Saya menunaikan janji-janji saya kepada pelanggan.

20 Saya mempercayai bahawan pelanggan saya akan memberi komen yang benar terhadap barangan atau perkhidmatan yang saya berikan.

\begin{tabular}{ll}
\hline Purata Min & $=4.54$ \\
Sisihan Piawai & $=0.39$ \\
Tahap & $=$ Tinggi \\
\hline
\end{tabular}

\section{Analisis Hubungan Antara Nilai Perniagaan Terhadap Tingkah Laku Keusahawanan Masyarakat Cina di Malaysia}

Ujian kolerasi Pearson digunakan untuk menguji hubungan antara nilai perniagaan terhadap tinglah laku keusahawanan masyarakat Cina di Malaysia. Jadual 2 menunjukkan hubungan antara nilai perniagaan terhadap tingkah laku keusahawanan Cina. Menerusi ujian pekali korelasi Pearson, nilai korelasi adalah: r $=0.293$ dan $P<.001$. Justeru, terdapat hubungan positif linear yang sangat lemah antara nilai perniagaan terhadap tingkah laku keusahawanan Cina. Hasil kajian ini menunjukkan hubungan yang menjurus ke arah positif tetapi menunjukkan pengaruh yang lemah dalam menentukan tingkah laku usahawan akibat seseorang peniaga berkiblat keuntungan sehingga nilai perniagaan diremehkan.

Jadual 2: Hubungan Antara Nilai Perniagaan terhadap Tingkah Laku Keusahawanan Cina

\begin{tabular}{cccc}
\hline Pemboleh Ubah & $\mathbf{r}$ & Sig & $\begin{array}{c}\text { Tahap Kekuatan } \\
\text { Hubungan }\end{array}$ \\
\hline Nilai Perniagaan & 0.293 & 0.000 & Lemah \\
\hline
\end{tabular}

*Korelasi signifikan pada aras $P<.001$

\section{Perbincangan Kajian}

Hasil dapatan tahap nilai perniagaan yang terdiri daripada empat domain seperti Guan Xi, maruah, kejujuran dan amanah daripada keusahawanan masyarakat Cina di Malaysia telah dianalysis di Jadual 1. Dapatan kajian menunjukkan nilai perniagaan keusahawanan masyarakat Cina di Malaysia mencapai min keseluruhan 4.54 dengan sisihan piawai 0.39. Kajian ini menunjukkan bahawa responden setuju dengan mereka sentiasa jujur dan amanah semasa berniaga. Hal ini bermakna usahawan masyarakat Cina sentiasa jujur dan amanah semasa berniaga. Masyarakat Cina lebih cenderung menjalinkan perniagaan dengan usahwanan yang mempunyai tahap jujur dan amanah yang tinggi (Wang, Siu, \& Barnes, 
2008). Nilai jujur dan amanah menjadi kelebihan daya saing bagi usahawanan yang dapat menjadikan diri mereka sebagai peniagan yang jujur dan amanah (Chu, Kara, Zhu \& Gok, 2011). Nilai jujur dan amanah merupakan faktor kejayaan paling kritikal dalam kalangan usahawanan masyarakat Cina (Chu \& Benzing, 2004). Seterusnya, responden bersetuju dengan mereka menggunakan bahasa yang sopan ketika berurus niaga. Dapatan kajian tersebut juga sama dengan kajian Gallo (2016) bahawa peniaga Cina sentiasa menghindari kesalahan yang mungkin boleh menyebabkan kehilangan maruah seseorang pelanggan. Tidak kurang juga, responden bersetuju mereka dapat mencipta reputasi perniagaan yang baik melalui pemeliharaan kehormatan diri dan penjagaan maruah pelanggan. Guo dan Lin (2015) menyatakan bahawa menjaga maruah merangkumi sikap atau tindakan tertentu yang membolehkan peniaga Cina untuk mencipta reputasi yang lebih baik di mata orang lain. Tambahan pula, kajian ini juga menunjukkan bahawa responden setuju dengan menjalin hubungan yang baik dengan pelanggan. Hubungan jaringan yang kuat antara perniagaan Cina merupakan keupayaan peniaga Cina untuk mempertahankan perniagaan dan memudahkan perniagaan dari segi peluang dan kos menjalankan perniagaan kerana ia berdasarkan kepercayaan dan bukannya kontrak (Wan Husin, 2013). Secara keseluruhan, tahap nilai perniagaan keusahawanan masyarakat Cina berada pada tahap tinggi. Perkara tersebut membuktikan usahawan masyarakat Cina mengamalkan nilai perniagaan yang diwarisan daripada Falsafah Konfusian semasa menjalankan perniagaan.

Dapatan kajian daripada ujian kolerasi menunjukkan hubungan positif yang signifikan antara nilai perniagaan terhadap tingkah laku keusahawanan masyarakat Cina di Malaysia. Terdapat hubungan positif linear yang sangat lemah antara nilai perniagaan terhadap tingkah laku keusahawanan Cina ( $\mathrm{r}=$ 0.293). Dapatan ini adalah selari dengan Arciniega (2017) dan Sara et al., (2017) yang menyatakan bahawa nilai perniagaan merupakan salah satu faktor terhadap tingkah laku usahawan. Hasil kajian ini menunjukkan hubungan yang menjurus ke arah positif tetapi menunjukkan pengaruh yang lemah dalam menentukan tingkah laku usahawan akibat seseorang peniaga berkiblat keuntungan sehingga nilai perniagaan diremehkan (Pulfrey \& Butera, 2013). Walau bagaimanapun, mengikut Konfusian, perniagaan tidak seharusnya menitikberatkan keuntungan semata-mata tetapi haruslah dapat memperbaiki masyarakat dan tidak memudaratkannya. Konfusian kurang menggalakkan konsep keuntungan dalam bidang perniagaan tetapi tidak mengakui bahawa bidang perniagaan mampu membantu masyarakat dan mencerna kesejahteraan social (Liu and Stening, 2016).

\section{Kesimpulan}

Nilai perniagaan adalah sangat penting dalam diri seseorang usahawan kerana nilai menentukan etika dalam sesuatu perniagaan yang perlu dipatuhi oleh komuniti peniaga dan dunia perniagaan (Ferrel, 2010). Dalam dunia perniagaan, isu tidak beretika dalam perniagaan merupakan masalah yang kiat meningkat akibat terlalu taasub kepada keuntungan meskipun kemajuan perniagaan dicapai (Rice, 2008). Kajian ini mengkaji tahap nilai perniagaan keusahawanan Cina dan hubungannya terhadap tingkah laku keusahawanan masyarakat Cina di Malaysia. Didapati tahap nilai perniagaan dalam kalangan usahawan masyarakat Cina di Malaysia berada pada tahap tinggi. Manakala faktor nilai perniagaan mempunyai hubungan positif yang lemah terhadap tingkah laku keusahawanan masyarakat Cina. Kajian ini mendapati keusahawanan masyarakat Cina mengamalkan nilai perniagaan yang diwarisan daripada Falsafah Konfusian semasa menjalankan perniagaan. Hubungan yang menjurus ke arah positif tetapi menunjukkan pengaruh yang lemah dalam menentukan tingkah laku usahawan akibat seseorang peniaga berkiblat keuntungan sehingga nilai perniagaan diremehkan.

Implikasi daripada kajian ini penting untuk memberi kesedaran kepada masyarakat Cina, Melayu dan India di Malaysia tentang nilai perniagaan terhadap tingkah laku keusahawanan dan dapat mendedahkan maklumat kepada masyarakat bahawa aktiviti keusahawanan bukan hanya dapat menyelesaikan masalah pengangguran sahaja, tetapi dapat meningkatkan taraf hidup dan membangun negara. Kajian ini juga dapat membantu agensi-agensi yang terlibat dalam bidang keusahawanan. Pihak agensi-agensi dapat mengetahui nilai perniagaan yang diterapkan oleh masyarakat Cina semasa menjalankan perniagaan. Maka, pihak agensi-agensi boleh mengambil langkah untuk memupuk nilai tertentu supaya perniagaan dapat dijalankan dengan lebih lancar. 


\section{Rujukan}

Ajzen, I. (1985). From Intentions To Actions: A Theory Of Planned Behavior. In J. Kuhl \& J.Beckmann (Eds.), Action-Control: From Cognition To Behavior. Heidelberg: Springer.

Ajzen, I. (2002). Perceived Behavioral Control, Self-Efficacy, Locus of Control and The Theory of Planned Behavior. Journal of Applied Social Psychology, 32(4): 665-683.

Ajzen, I. (1991). The Theory of Planned Behavior. Organizational Behavior and Human Decision Processes, 50(2): 179-211.

Ajzen, I., dan Fishbein, M. (1980). Understanding Attitudes and Predicting Social Behavior. Englewood Cliffs, NJ: Prentice-Hall.

Arciniega, L. M., Stanley, L. J., Puga-Méndez, D., Obregón-Schael, D., \& Politi-Salame, I. (2017). The Relationship Between Individual Work Values and Unethical Decision-Making and Behavior at Work. Journal of Business Ethnics, 158, 11331148 .

de Vaus, David. (2004). Structured Questionnaires and Interviews. Handbook of Research Methods for Nursing and Health Science, 347-392.

Rice, G., (2008). Islamic Ethics and The Implications for Business. Journal of Bussiness Ethics, 18, 345-358.

Chin, Yee Mun. (2013). Budaya dan Profil Usahawan Cina Malaysia. Journal of Chinese Literature and Culture, 1(2), 67-94.

Chow, H.I. (2005). The Impact of Institutional Context on Human Resource Management in Three Chinese Societies. Employee Relations: An International Journal, 26(6), 626-642.

Chu, H.M. and Benzing, C. (2004). Vietnamese Entrepreneurs: Motivation, Problems, and Success Factors. Journal of Global Business, 15(28), 25-33.

Chu, Hung \& Kara, Orhan \& Zhu, Xiaowei \& Gok, Kubilay. (2011). Chinese Entrepreneurs: Motivations, Success Factors, Problems, and Business-Related Stress. Journal of Chinese Entrepreneurship, 3, 84-111.

Ferrel, Thorne, Ferrel. (2010). Social Responsibility \& Business. New Jersey: SouthWestern-Cengage Learning.

Fleishman, E. A. (1958). A Relationship Between Incentive Motivation and Ability Level in Psychomotor Performance. Journal of Experimental Psychology, 56, 78-81.

Gallo, Ilaria. (2016). Mianzi and Guanxi in the Chinese Culture: Two Fundamental Concepts.

Geographical Association (2020). Retrieved from Website: https://www.geography.org.uk/teaching-resources/singapore-malaysia/Couldethnic-tensions-destroy-the-Malaysia-economic-miracle

Giacalone, R. A., Promislo, M., \& Jurkiewicz, C. (2016). Ethical Impact Theory: How Unethical Behavior at Work Affects Individual Well-Being. Global Encyclopedia of Public Administration, Public Policy, and Governance, 1-5.

Guo, Xiaolin \& Lin, Derong. (2015). A Literature Review of Face Consciousnes and Local Consumer Behavior in China. Foreign Economics \& Management, 63-70.

Hair, J.F., Black, W.C., Babin, B.J., \& Anderson, R.E. (2010). Multivariate Data Analysis. (Seventh Edition). New Jersey: Prentice Hall, Upper Saddle River.

Hartman, L. P. (2005). Perspectives in Business Ethics. 3rd Edn., New York: McGraw Hill/Irwin.

He, Qicai. (2012). The Economic Activities and Development of Chinese Businessmen in Malaysia. China Academix Journal Electronic Publishing House, 43-49.

Heider, F. (1944). Social Perception and Phenomenal Casuality. Psychological Review, 51, 358-374.

Hisrish, R.D., Peters, M.P. \& Shephard, D.A. (2008). Entrepreneurship. Singapore: McGraw- Hill.

Hulpke, John \& Lau, Cubie L.L. (2008). Business Ethics in China: A Human Resource Management Issue? Chinese Economy, 41, 58-67.

Kirkley, William. (2016). Entrepreneurial Behaviour: The Role of Values. International Journal of Entrepreneurial Behavior \& Research, 22, 290-328. 
Krejcie, R. V., \& Morgan, D. W. (1970). Determining Sample Size for Research Activities. Educational and psychological measurement, 30(3), 607-610.

Lee, Shao Lin. (2015). Teknik Mempromosikan Produk.

Lewin, K., Dembo, T., Festinger, L. A., \& Sears, P. S. (1944). Level of Aspiration. In J. Mcv. Hunt (Ed.), Personality and The Behavior Disorder 1, 333-378.

Liao, Kun-Hsi. (2016). Impact of Traditional Chinese Culture on Business-To-Business Relationship Marketing and Service Firm Performance. Journal of BusinessTo-Business Marketing, 277-291.

Liu, T. Q., \& Stening, B. W. (2016). The Contextualization and De-Contextualization of Confucian Morality: Making Confucianism Relevant to China's Contemporary Challenges in Business Ethics. Asia Pacific Journal of Management, 33(3), 821-841.

Locke, E. A., Mento, A. J., \& Katcher, B. L. (1978). The Interaction of Ability and Motivation In Performance: An Exploration Of The Meaning OfModerators. Personnel Psychology, 31, 269-280.

Mohd Mizan Aslam. (2012). Etika Dalam Perniagaan dan Pencarian Menuju Integriti. International Journal of Business and Technopreneurship, 2(2), 369387.

Mohd Zulfadli, (2010, Jan 28). mymubin.com. Retrieved from mymubin.com Web site: http://mymubin.com/v1/article/kepentingan-etika-perniagaan.html

Norita Deraman, Armanurah Mohamad, Habshah Bakar, Norashidah Hashim, \& Ooi Yeng Keat. (2010). Keusahawanan Teori dan Praktis (Kedua). McGraw-Hill Education.

Nor Hazwani Halim \& Sheerad Sahid. (2020). Kemahiran Kesediaan Kerja, Efikasi Kendiri, Tingkah Laku Keusahawanan dan Eksplorasi Kerjaya dalam kalangan Graduan. Akademika 90(Isu Khas 3), 2020: 155-165.

Park, S. H., \& Luo, Y. (2001). Guanxi and Organizational Dynamics: Organizational Networking in Chinese Firms. Strategic Management Journal, 22(5), 455-477.

Pulfrey, C., \& Butera, F. (2013). Why Neoliberal Values of Self-Enhancement Lead to Cheating in Higher Education: A Motivational Account. Psychological Science, 24, 2153-2162.

Ruvolo Claudia. (2018). The Influence of Chinese Culture in the Italian Business in China.

Sirkin, R. M. (2005). Statistics for The Social Sciences. Sage Publications. Southeast Asia.

Vroom, V. H. (1964). Work and Motivation. New York: Wiley.

Wan Husin, Wan Norhasniah. (2013). Business Dominance Among the Malays and Chinese in Malaysia from a Civilizational Perspectives. International Journal of Social Science and Humanity, 360-364.

Wang, C. L., Siu, N. Y. M., \& Barnes, B. R. (2008). The significance of trust and renqing in the longterm orientation of Chinese business-to-business relationships. Industrial Marketing Management, $37(7), 819-824$.

Wang, Changzheng, Zhou, Xuechun, \& Huang, Minxue. (2012). Seeking Similarity or Reserving Diferences: How Face Facilitates or Restricts Consumer's Need for Uniqueness. Journal of Marketing Science, 18-34.

Wong, Y.H., Leung, T.K.P. \& Ngai, E. (2008). A model of guanxi development: F lexibility, commitment and capital exchange. Total Quality Management : 875887.

Yusof, A. A. \& A. Bashir, (2008). The management of Islamic businesses. Sintok: Universiti Utara Malaysia. 